\title{
Coronary Hemodynamics and Regional Myocardial Metabolism in Experimental Aortic Insufficiency
}

\author{
Douglas M. Griggs, Jr., and Chin Chi Chen \\ From the Department of Physiology, University of Missouri Medical School, \\ Columbia, Missouri 65201
}

\begin{abstract}
A в S T R A C T Acute aortic valvular insufficiency was induced in open chest dogs by employing a special intravascular cannula, or by rupturing an aortic valve leaflet. Phasic and mean coronary flow were assessed in some animals, while in others data were obtained on arterial and coronary sinus blood lactate, pyruvate, $\mathrm{Po}_{2}, \mathrm{Pco}_{2}$, and $\mathrm{pH}$, and on myocardial tissue lactate, pyruvate, and water content in the outer and inner halves of the free wall of the left ventricle. Results showed that in acute aortic insufficiency diastolic coronary flow decreased as a function of aortic diastolic pressure, but systolic coronary flow increased in such proportion that mean coronary flow did not decrease. With moderate reductions in aortic diastolic pressure due to aortic insufficiency, myocardial blood flow was judged to be nutritionally adequate in both the outer and inner regions of the left ventricle. With more severe reductions in aortic diastolic pressure, the inner region exihibited biochemical signs of anaerobic metabolism. The presence of these metabolic changes could be correlated with either of two previously described pressure indexes. These findings suggest that the reduced coronary perfusion pressure and the intramyocardial tissue pressure gradient can be compensated for by autoregulation in some cases of aortic insufficiency, but in others such compensation may be incomplete, in which case oxygen delivery to the subendocardium will be inadequate to meet local tissue oxygen needs.
\end{abstract}

\section{INTRODUCTION}

It is apparent from the high incidence of angina pectoris in patients with severe aortic insufficiency (1) that an imbalance between myocardial oxygen supply and demand is a common problem in this disorder. Presumably,

During the period of this investigation Dr. Griggs was the recipient of a Research Career Development Award from National Institutes of Health.

Received for publication 27 July 1973 and in revised form 19 December 1973.

The Journal of Clinical Investigation Volume 53 June 1974·1599-1606 this is related to the low perfusion pressure in the coronary circulation during diastole-the time when coronary flow is normally greatest-and the greater than normal energy requirements of the hyperfunctioning left ventricle. Recently, Buckberg, Fixler, Archie, and Hoffman (2) demonstrated that when aortic diastolic pressure was lowered in the dog by opening a large arteriovenous fistula, blood flow in the wall of the left ventricle became uneven and lower in the subendocardium than the subepicardium. They correlated the regional flow changes with a special pressure index they developed to assess the balance between oxygen supply and demand in the subendocardium. It was not possible, however, to determine from the flow data or the pressure index to what extent, if any, the metabolic needs of the subendocardium were being under met when aortic diastolic pressure was reduced.

In previous animal studies from our laboratory $(3,4)$ we showed that when pressure in the coronary circulation was independently reduced by coronary constriction, the subendocardium developed metabolic signs of inadequate oxygen delivery. This finding correlated well with a pressure index developed by us to predict the presence of uneven myocardial blood flow (5). It would appear from the study of Buckberg et al. (2) that similar results might be obtained in aortic insufficiency. Accordingly, the present study was undertaken to determine whether the subendocardium exhibits metabolic signs of inadequate oxygen delivery in animals with experimentally produced aortic insufficiency, and, if so, whether this is predictable from the hemodynamic findings.

\section{METHODS}

Studies were performed on 30 mongrel dogs, whose weights averaged $21.2 \pm 0.7$ (SE) $\mathrm{kg}$. The animals had been screened for microfilariae, medicated against rabies and intestinal parasites, and maintained on a nourishing diet for at least 30 days. They were presedated with morphine sulfate, 2 $\mathrm{mg} / \mathrm{kg}$, s.c., and anesthetized with pentobarbital, $30 \mathrm{mg} / \mathrm{kg}$, i.v.; additional pentobarbital was administered as needed during the experiment. The trachea was intubated and 


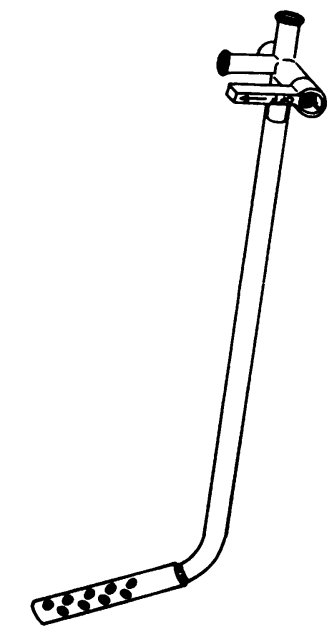

Figure 1 Diagram of cannula used to produce acute aortic insufficiency. The lower end was introduced into the aorta via the left subclavian artery and the tip was advanced across the aortic valve into the left ventricle. Blood escaped into the ventricle during diastole through the holes in the cannula located on the aortic side of the valve. Pressure was monitored through the stopcock during passage of the cannula across the aortic valve. See text for cannula dimensions.

respiration was maintained with a Harvard respirator (Harvard Apparatus Co., Inc., Millis, Mass.).

Aortic insufficiency was produced in 17 animals after a left thoracotomy by introducing a special tube (Fig. 1) into the aorta via the ligated left subclavian artery and passing it retrograde across the aortic valve. This tube, henceforth referred to as an "aortic insufficiency cannula," consisted of a lower thin walled aluminum section with multiple side holes and an upper plexiglass section fitted with a stopcock at the end. Although cannulas of different sizes were employed, typically, the aluminum section was $4.5 \mathrm{~cm}$ in length and $6 \mathrm{~mm}$ in external diameter, and the plexiglass section was $14 \mathrm{~cm}$ in length and $7 \mathrm{~mm}$ in external diameter. The sideholes in the aluminum section were $3 \mathrm{~mm}$ in diameter. When the cannula tip was passed retrograde into the left ventricle with the stopcock closed, aortic valvular insufficiency occurred from the passage of blood during diastole into the ventricle through the side holes located above the valve. Blood loss during insertion of the cannula into the aorta was minimized by clamping the subclavian artery close to the aorta and stretching the opened vessel over the side holes before removing the clamp. The plexiglass tube was filled with saline before the cannula was inserted, and later bled to remove any air trapped in the system during insertion. Pressure was monitored through the stopcock while manipulating the cannula to determine when the tip entered the ventricle. Pressure signals were also obtained from the aorta through a side hole catheter advanced from the femoral artery and from the left ventricle through a large bore needle inserted into the apex. All signals were recorded on a multichannel oscillograph (model Dr-8, Electronics for Medicine, Inc., White Plains, N. Y.) and a multichannel tape recorder (model 3907B, Hewlett-Packard Co., Palo Alto, Calif.). A catheter was inserted into the external jugular vein and guided by palpation into the coronary sinus for blood sampling. Anticoagulation was achieved with heparin, administered intravenously in a dose of $5 \mathrm{mg} / \mathrm{kg}$.

The experimental protocol and assay procedures for the metabolic studies were as follows: A control period was established after introducing the aortic insufficiency cannula into the aorta, but before advancing the tip into the left ventricle. During this period recordings were made of aortic and left ventricular pressures and blood samples were obtained from the arterial and coronary sinus catheters. Blood samples were drawn anaerobically for gas and $\mathrm{pH}$ analysis in a blood electrode system (model 113-S1, Instrumentation Laboratories) and in cold glass syringes for precipitation immediately in $6 \%$ perchloric acid for lactate (6) and pyruvate (7) analysis. Next, the tip of the aortic insufficiency cannula was manipulated into the ventricle while pressure was monitored at the external end of the cannula. This maneuver was usually completed in $15-30 \mathrm{~s}$, but occasionally several minutes were required to cross the aortic valve. The time of induction of aortic insufficiency was noted, and the cannula was held in the most optimal position with a clamp. Pressure signals were monitored continuously. $13 \mathrm{~min}$ after the onset of aortic insufficiency arterial and coronary sinus blood samples were obtained, and at $15 \mathrm{~min}$ a transmural tissue sample of the beating left ventricle was obtained by using a cylindrical cutting tool mounted in an electric hand drill. The sampling site was located lateral to the crux formed by the anterior descending and circumflex branches of the left coronary artery, and was selected because it avoided the papillary muscles. The mean weight of all tissue samples obtained in the study was $1.17 \pm 0.04 \mathrm{~g}$ and the mean sampling time was $3.1 \pm 0.1 \mathrm{~s}$. The sample was submerged in liquid Freon, precooled in liquid nitrogen for rapid tissue freezing. Extraneous blood was removed from the surface of the frozen tissue sample, which was then split as evenly as possible into outer and inner halves. Each portion was weighed, pulverized, and transferred to a chilled Potter-Elvehjem tube for extraction with $6 \%$ perchloric acid during grinding. After centrifugation at $13,000 \mathrm{~g}$ for $30 \mathrm{~min}$ in the cold, the clear supernate was removed. The residue was resuspended in an additional aliquot of perchloric acid for a second extraction. The supernates obtained from the two extraction procedures were combined into a single filtrate. Aliquots of both blood and tissue filtrates were analyzed immediately for pyruvate. The remaining filtrate was stored in a freezer and analyzed for lactate later, usually within $24 \mathrm{~h}$. All analyses were performed in duplicate. Tissue residues were dried in an oven to constant weight and the percent water content was calculated from the original tissue weight. Identical studies were performed on eight control animals who underwent all surgical procedures except ligation of the left subclavian artery and insertion of the aortic insufficiency cannula.

The effect of aortic insufficiency on phasic coronary flow was examined in five additional animals. In two of these animals the circumflex branch of the left coronary artery was cannulated on the surface of the heart and perfused from a circuit attached to the external end of a modified aortic insufficiency cannula. The cannula was modified by (a) placing a partition in the lumen at the aluminumplexiglass junction, $(b)$ making an additional side hole above this junction, and (c) replacing the stopcock with a rubber sleeve for connecting the external circuit. With the continuity of the cannula lumen interrupted at the aluminum-plexiglass junction, pressure in the external circuit was derived solely from the aorta. Incorporated into the 
external circuit, which consisted of curved plexiglass tubing, was a cannulating type electromagnetic flow transducer. A Biotronex flowmeter (BL 610, Biotronex Laboratory, Inc., Silver Spring, Md.) was used, and the zero flow signal was obtained by momentarily occluding the circuit. The flowmeter was calibrated in vitro by making timed collections of whole blood in a graduated cylinder, and plotting the relationship between flow rate and signal deflection. In the other three animals total left coronary flow was measured before and after rupturing an aortic valve leaflet. Flow was measured through a special stainless steel cannula (3-5) consisting of a lower L-shaped, doublelumen shaft and an upper single-lumen loop. When the cannula shaft was introduced into the aorta via the ligated left subclavian artery, and its tip firmly secured in the main left coronary artery segment by an externally placed snare, blood from the root of the aorta entered a sidehole in the shaft of the cannula, passed up one lumen to the loop, and returned via the other lumen to the coronary artery. The stainless steel loop contained a $1-\mathrm{cm}$ section of rubber tubing, side taps, and a cannulating type electromagnetic flow transducer. A zero-flow signal was obtained by momentarily occluding the rubber tubing section. After normal flow was measured in the vessel, the snare was released, and the cannula tip was withdrawn from the coronary ostium into the aorta. Then, an aortic valve leaflet was ruptured blindly by forcing the tip of the cannula against it. The cannula tip was resecured in the main left coronary artery for repeat flow measurements. The entire procedure following the control measurements required only a few minutes.

Aortic-ventricular pressure index. This index is comparable to the previously described coronary-ventricular pressure index (5), which was shown in coronary constriction studies to predict the occurrence of uneven blood flow in the wall of the left ventricle. It is estimated from the areas inscribed beneath the aortic and left ventricular pressure curves during one cardiac cycle and is obtained by subtracting the ventricular diastolic pressure area from the total aortic pressure area and dividing the difference by the ventricular systolic pressure area. The postulation of this index was based upon a consideration of forces generally assumed to play a role in regulating the transmural distribution of myocardial blood flow. Considering the ventricular wall as outer and inner halves, the tissue compressive force during systole is greater in the inner half (8). This compressive force is a function of ventricular systolic pressure. Opposing the compressive force is the intravascular force, which is a function of coronary artery systolic pressure. From previous evidence (8) it is likely that the compressive force approaches and exceeds the intravascular force at some point between the epicardial and endocardial surfaces of the left ventricular wall. It follows that the ratio of systolic blood flow in the outer and inner halves is related to the location of this point, and thereby related to the ratio of coronary artery to ventricular pressure during systole. Although this systolic pressure ratio is essentially unaltered in aortic insufficiency, it is altered in a number of other conditions, such as coronary artery stenosis, aortic valvular stenosis, and subaortic valvular stenosis. During diastole the tissue compressive force is negligible at normal left ventricular diastolic pressures, and the ratio of blood flow in the outer and inner halves is primarily dependent upon local vasomotor. tone and the effective coronary perfusion pressure (aortic minus left ventricular pressure). Vasomotor tone is presumably less in the inner half because of lower flow in this region during systole. Predicted flow is, therefore, greater in the inner than the outer half during diastole. However, when coronary diastolic pressure is reduced, this capacity for greater diastolic flow in the inner half is reduced due to loss of autoregulation, and to a low effective coronary perfusion pressure. Under these circumstances the distribution of myocardial blood flow becomes primarily dependent upon the tissue compressive force during systole.

Statistical procedures. The 17 animals with aortic insufficiency from which myocardial tissue data were obtained exhibited a wide range of aortic diastolic pressures at the time of tissue sampling, and therefore, they did not constitute a homogenous experimental group. However, they could be separated into two meaningful groups based upon whether a metabolic difference was or was not found between the outer and inner halves of the myocardium. Differences from normal were established for the measured hemodynamic and metabolic variables in each of these groups. The Wilcoxon matched-pairs signed-rank test (ref. 9, p. 75) was used for evaluating tissue differences between the outer and inner halves of the myocardium in the same animal. The Kruskal-Wallis $\mathrm{H}$ test (ref. 9, p. 184) was used for evaluating differences between normal animals and each of the two experimental groups. If the $\mathrm{H}$ test gave a significant value $(P<0.05)$, further analysis was performed by using the Mann-Whitney U test (ref. 9, p. 116).

\section{RESULTS}

Fig. 2 illustrates the hemodynamic changes produced in one experiment with the aortic insufficiency cannula. In this experiment the circumflex branch of the left coronary artery was cannulated externally and perfused from the aorta to obtain a measurement of phasic coronary flow. Phasic aortic flow was also estimated in this one experiment by placing a cuff type electromagnetic flow transducer on the aortic arch. The zero-flow signal for the aortic flowmeter was approximated from the flow pattern. When the cannula tip was advanced into the ventricle (Tracing A), a widening of the aortic pressure pulse occurred which was superimposed on the cylic pressure changes related to respiration. The amplitude of the aortic flow signal increased due both to an increase in peak forward flow and to the development of retrograde flow. Coronary flow became strikingly different in that the systolic component increased and the diastolic component decreased. Mean coronary flow did not decrease. When the cannula was retracted into the aorta (Tracing B) an increase in diastolic coronary flow ensued which was transiently greater than normal, indicating previous coronary vasodilation as the result of autoregulation.

The influence of aortic diastolic pressure on the percentage of stroke coronary flow occurring in diastole was examined in five animals. In two animals circumflex flow was measured, and aortic diastolic pressure was varied as depicted in Fig. 2. In three animals total left coronary flow was measured through the self-perfusing coronary cannula, before and after rupturing an aortic 


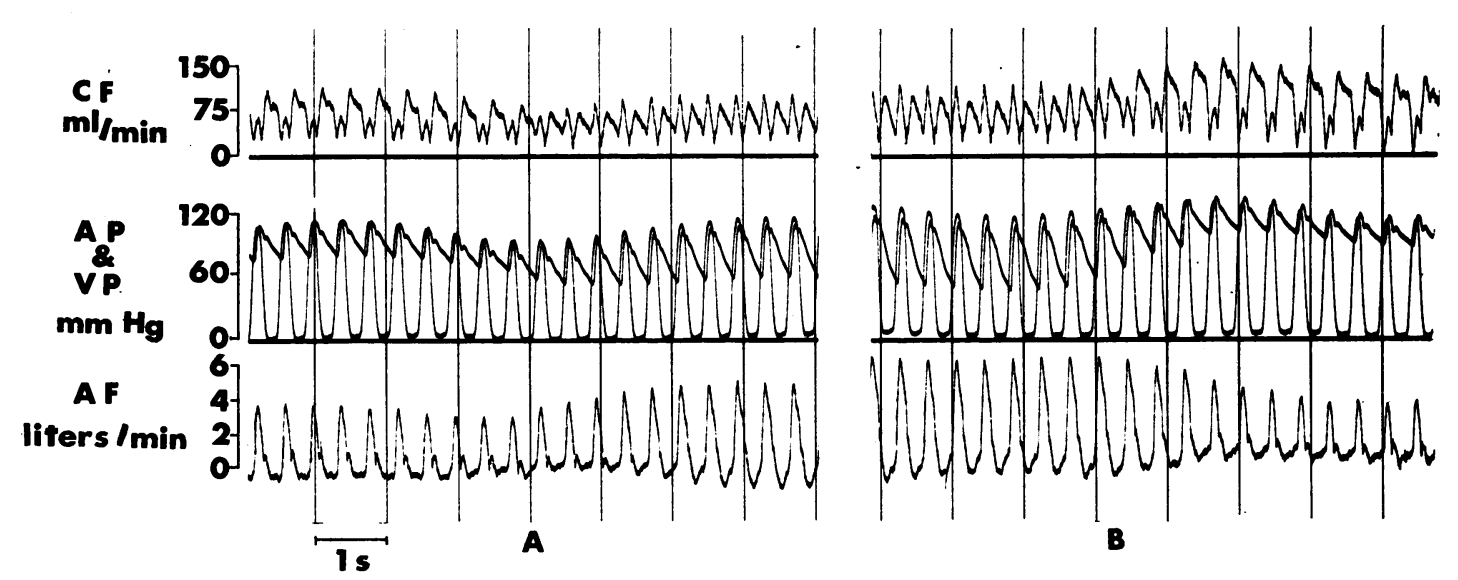

FiguRE 2 (A) Record from an experiment illustrating changes in instantaneous coronary flow $(C F)$, aortic pressure $(A P)$, and aortic flow $(A F)$ during induction of aortic insufficiency with the special cannula. Also shown is left ventricular pressure $(V P)$. The slow cycle pressure changes were related to respiration. (B) Later record illustrating changes during return to normal by withdrawal of cannula from the ventricle.

valve leaflet with the tip of the coronary cannula. The results, shown in Fig. 3 , reveal a curvilinear relationship between aortic diastolic pressure and the percentage of coronary flow occurring in diastole. Despite the marked reduction in coronary diastolic flow at low aortic diastolic pressures, mean flow was not depressed due to a reciprocal increase in systolic cornary flow. For instance, the individual mean flow values in the three animals in which total left coronary flow was measured were 72 , 64 , and $67 \mathrm{ml} / \mathrm{min}$ before producing aortic insufficiency, and 70,69 , and $79 \mathrm{ml} / \mathrm{min}$, respectively, afterwards.

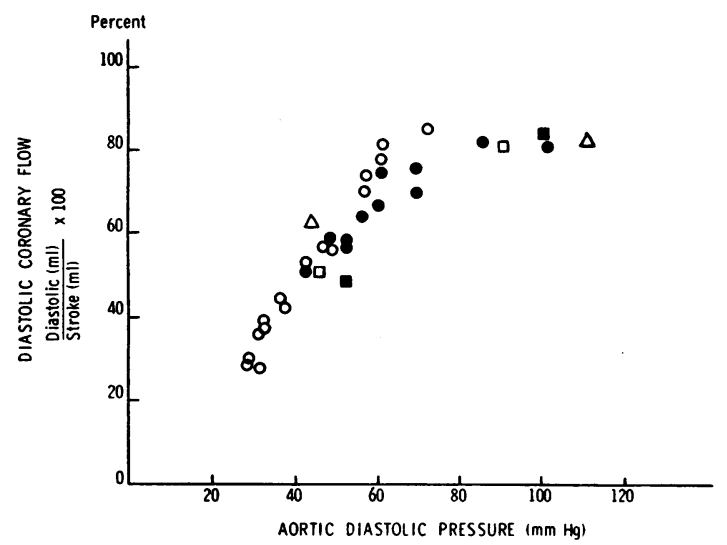

FIGURE 3 Plot showing relationship between aortic diastolic pressure and percent diastolic coronary flow in five animals. The open and closed circles are multiple data points for two animals in which circumflex flow was measured after repositioning the aortic insufficiency cannula, and the open and closed squares and open triangles are paired data points for three animals in which total left coronary flow was measured before and after rupturing an aortic valve leaflet.
Heart rate and left ventricular pressure changes were negligible in these studies.

An analysis of the myocardial tissue findings in 17 animals with aortic insufficiency revealed a curvilinear relationship between aortic diastolic pressure and the tissue lactate concentration in the inner half of the myocardium relative to that in the outer half (Fig. 4). Animals with aortic diastolic pressures in the upper range exhibited inner region lactate levels essentially the same as those in the outer region (unity $=100 \%$ ), whereas animals with aortic diastolic pressures in the lower range exhibited relatively higher inner region

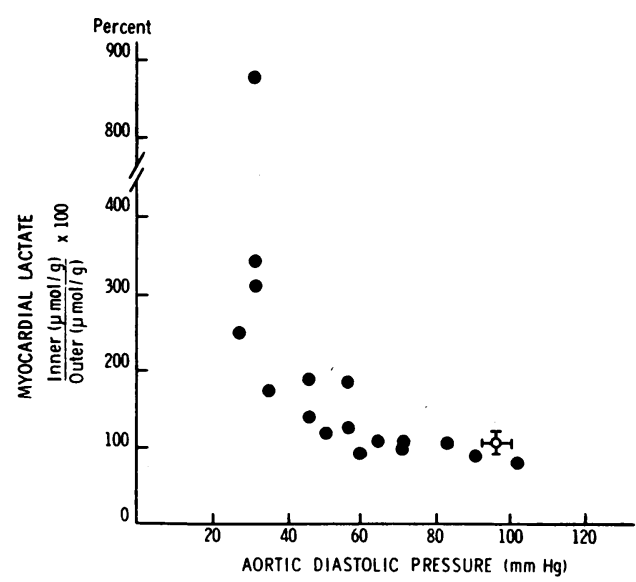

FIgURE 4 Plot showing relationship between aortic diastolic pressure and the tissue lactate level in the inner region of the ventricle, expressed as a percentage of the outer region level (unity $=100 \%$ ). Closed circles-points for individual animals with aortic insufficiency. Open circlepoint for mean data from eight normal animals. Limit signs on open circle designate standard error of the mean. 
levels. This dependency on pressure of myocardial tissue lactate distribution was examined further by using the aortic-ventricular pressure index as the pressure variable instead of aortic diastolic pressure. This plot is shown in Fig. 5. This index effectively separated the animals into two groups, one with inner region lactate levels substantially above $(>50 \%)$ the outer region levels, and the other with smaller or essentially no regional lactate differences. The critical aortic-ventricular pressure index value separating these two groups was 1.37.

Another plot (not shown) was constructed by using the diastolic pressure time index/left ventricular tension time index (DPTI/TTI) ${ }^{1}$ described by Buckberg et al. (2) as the pressure variable. A similar relationship was evident with this index, with the critical value for separating the group with the higher inner region lactate value being 0.45 . However, the separation was slightly less distinct using DPTI/TTI due to the inclusion of data for one animal with a relatively small regional lactate difference in the low index group.

Statistical procedures were used to determine whether the absolute tissue lactate values were different from normal for the two animal groups separated by the aortic-ventricular pressure index value of 1.37 . The animals with higher index values are designated in the text as "Experimental Group I" and those with lower index values as "Experimental Group II." The statistical findings on the lactate data, as well as on data obtained on the other measured metabolic and hemodynamic variables, are presented along with normal data in Tables I-III. The important findings are summaried as follows.

Normal group. The data were similar to other normal data reported from our laboratory $(3,4,10)$. As noted before, no differences were found between the outer and inner regions of the left ventricle for tissue

${ }^{1}$ Abbreviation used in this paper: DPTI/TTI, diastolic pressure time index/left ventricular tension time index.

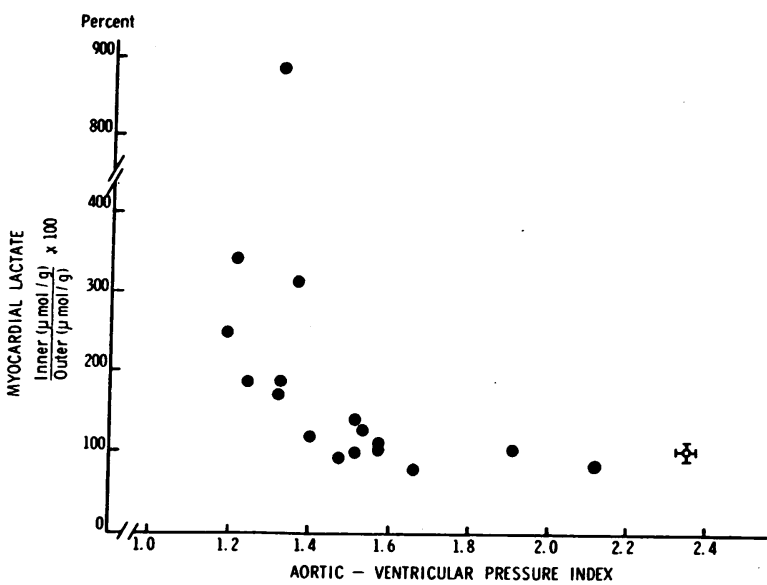

FIGURE 5 Plot showing relationship between aortic-ventricular pressure index (see text) and inner region lactate, as described in Fig. 4.

lactate, pyruvate, lactate-to-pyruvate ratio, or water content.

Experimental group I. Aortic diastolic pressure was below normal, averaging $70 \pm 6 \mathrm{~mm} \mathrm{Hg}$, but there were no significant differences from the normal animals in any of the other measured hemodynamic or metabolic variables. As in the normal animals, no outer to inner region differences were found in the tissue substrate levels, the lactate-to-pyruvate ratio, or the water percentage.

Experimental group II. Aortic diastolic pressure was below normal, averaging $37 \pm 4 \mathrm{~mm} \mathrm{Hg}$. Notable negative findings include normal aortic systolic and left ventricular end diastolic pressures. Blood data analysis revealed a higher than normal coronary sinus lactate level, and a less than normal myocardial lactate extraction, but a coronary sinus blood oxygen tensicn that was not statistically different from normal. Analysis of the tissue data showed that the inner region lactate level was above the outer region level for the same animals

TABLE I

Hemodynamic Data on Normal and Experimental Animals

\begin{tabular}{|c|c|c|c|c|}
\hline Animal group & Heart rate & $\begin{array}{c}\text { Aortic } \\
\text { systolic P }\end{array}$ & $\begin{array}{c}\text { Aortic } \\
\text { diastolic P }\end{array}$ & $\begin{array}{l}\text { Vent. end } \\
\text { diastolic P }\end{array}$ \\
\hline & beats/min & $m m \mathrm{Hg}$ & $m m \mathrm{Hg}$ & $m m \mathrm{Hg}$ \\
\hline Normal $(n=8)$ & $144 \pm 17$ & $117 \pm 5$ & $96 \pm 4$ & $6 \pm 1$ \\
\hline $\begin{array}{l}\text { Experimental I }(n=10) \\
\qquad P^{*}\end{array}$ & $\begin{array}{l}175 \pm 12 \\
\mathrm{NS}\end{array}$ & $\begin{array}{l}128 \pm 6 \\
\text { NS }\end{array}$ & $\begin{array}{l}70 \pm 6 \\
<0.05\end{array}$ & $\begin{array}{l}7 \pm 1 \\
\text { NS }\end{array}$ \\
\hline $\begin{array}{l}\text { Experimental II }(n=7) \\
\quad P^{*}\end{array}$ & $\begin{array}{l}182 \pm 10 \\
\text { NS }\end{array}$ & $\begin{array}{l}107 \pm 7 \\
\text { NS }\end{array}$ & $\begin{array}{l}37 \pm 4 \\
<0.01\end{array}$ & $\begin{array}{l}7 \pm 2 \\
\mathrm{NS}\end{array}$ \\
\hline
\end{tabular}

Values are mean \pm SEM.

* Compared to normal. 
TABLE II

Blood Data on Normal and Experimental A nimals

\begin{tabular}{|c|c|c|c|c|c|c|c|c|c|c|c|c|}
\hline \multirow[b]{2}{*}{ Animal group } & \multicolumn{3}{|c|}{ Lactate } & \multicolumn{3}{|c|}{ Pyruvate } & \multicolumn{2}{|c|}{$\mathrm{PO}_{2}$} & \multicolumn{2}{|c|}{$\mathrm{Pco}_{2}$} & \multicolumn{2}{|c|}{$\mathrm{pH}$} \\
\hline & Art. & Cor. sin. & Extract. & Art. & Cor. sin. & Extract. & Art. & Cor. sin. & Art. & Cor.sin. & Art. & Cor. sin. \\
\hline & \multicolumn{2}{|c|}{$m M^{*}$} & $\% \ddagger$ & \multicolumn{2}{|c|}{$m M$} & $\%$ & \multicolumn{2}{|c|}{$m m \mathrm{Hg}$} & \multicolumn{2}{|c|}{$m m H g$} & & \\
\hline $\begin{array}{l}\text { Normal }(n=8) \\
\text { SE } \pm\end{array}$ & $\begin{array}{l}1.013 \\
0.184\end{array}$ & $\begin{array}{l}0.503 \\
0.052\end{array}$ & $\begin{array}{r}46.3 \\
4.0\end{array}$ & $\begin{array}{l}0.088 \\
0.011\end{array}$ & $\begin{array}{l}0.068 \\
0.008\end{array}$ & $\begin{array}{r}18.7 \\
6.8\end{array}$ & $\begin{array}{r}82.0 \\
2.0\end{array}$ & $\begin{array}{r}18.3 \\
0.7\end{array}$ & $\begin{array}{r}36.3 \\
0.9\end{array}$ & $\begin{array}{r}52.7 \\
2.5\end{array}$ & $\begin{array}{l}7.41 \\
0.03\end{array}$ & $\begin{array}{l}7.35 \\
0.01\end{array}$ \\
\hline $\begin{array}{l}\text { Experimental I }(n=10) \\
\text { SE士 } \\
P \S\end{array}$ & $\begin{array}{l}1.336 \\
0.212 \\
\text { NS }\end{array}$ & $\begin{array}{l}0.929 \\
0.175 \\
\text { NS }\end{array}$ & $\begin{array}{r}33.7 \\
4.1 \\
\mathrm{NS}\end{array}$ & $\begin{array}{l}0.084 \\
0.010 \\
\text { NS }\end{array}$ & $\begin{array}{c}0.055 \\
0.006 \\
\text { NS }\end{array}$ & $\begin{array}{r}36.2 \\
5.1 \\
\text { NS }\end{array}$ & $\begin{array}{r}77.4 \\
5.6 \\
\text { NS }\end{array}$ & $\begin{array}{r}15.3 \\
1.0 \\
\text { NS }\end{array}$ & $\begin{array}{r}34.0 \\
1.0 \\
\text { NS }\end{array}$ & $\begin{array}{r}50.5 \\
1.7 \\
\text { NS }\end{array}$ & $\begin{array}{l}7.39 \\
0.01 \\
\text { NS }\end{array}$ & $\begin{array}{c}7.33 \\
0.00 \\
\text { NS }\end{array}$ \\
\hline $\begin{array}{l}\text { Experimental II }(n=7) \\
\text { SE } \pm \\
P \S\end{array}$ & $\begin{array}{l}1.537 \\
0.221 \\
\text { NS }\end{array}$ & $\begin{array}{r}1.177 \\
0.260 \\
<0.01\end{array}$ & $\begin{array}{c}25.5 \\
7.0 \\
<0.05\end{array}$ & $\begin{array}{c}0.094 \\
0.013 \\
\text { NS }\end{array}$ & $\begin{array}{c}0.061 \\
0.011 \\
\text { NS }\end{array}$ & $\begin{array}{c}36.1 \\
4.3 \\
\mathrm{NS}\end{array}$ & $\begin{array}{r}76.0 \\
6.7 \\
\text { NS }\end{array}$ & $\begin{array}{r}15.8 \\
1.6 \\
\mathrm{NS}\end{array}$ & $\begin{array}{r}35.5 \\
2.1 \\
\text { NS }\end{array}$ & $\begin{array}{r}55.5 \\
2.1 \\
\text { NS }\end{array}$ & $\begin{array}{c}7.38 \\
0.04 \\
\text { NS }\end{array}$ & $\begin{array}{l}7.30 \\
0.01 \\
\text { NS }\end{array}$ \\
\hline
\end{tabular}

* Calculated per liter of whole blood.

$\ddagger($ (Art. - Cor. sin. $) /$ Art. $) \times 100$

$\$$ Compared to normal.

and above the inner region level for the normal animals. Similarly, the inner region tissue lactate to pyruvate ratio was above that in the outer region for the same animals and above that in the inner region for the normal animals. A higher than normal tissue water percentage was noted in both outer and inner regions, but no difference was found between these regions in the same animals.

\section{DISCUSSION}

In a careful evaluation of 100 patients with severe aortic insufficiency who were being considered for valvular surgery, Segal, Harvey, and Hufnagel (1) noted that the incidence of classic angina pectoris was $38 \%$. The mean age of the anginal group was $33.7 \mathrm{yr}$, and autopsies on those who succumbed revealed no evidence of coronary artery disease or coronary ostial narrowing. The authors suggested three possible mechanisms for angina in these patients: (a) a reduction in coronary flow due to the low aortic diastolic pressure, (b) a "sucking" action on the coronary arteries by regurgitant blood (Bernouilli's principle), and (c) relative coronary insufficiently related to the increased muscle mass of the left ventricle. The question of reduced coronary flow in patients with aortic insufficiency was investigated by Rowe et al. (11) who used the nitrous oxide method to estimate mean coronary flow per unit of muscle mass at rest and during exercise. Coronary flow was found to be within normal limits at rest and to be increased in a normal manner during exercise in patients with aortic insufficiency, some of whom had a positive history for angina pectoris. The authors concluded that their study did not identify the cause of angina in aortic insufficiency, and they conjectured that the mechanism was undoubtedly complex in this disorder.

In the present study data obtained on directly metered total left coronary flow before and after the induction of aortic insufficiency revealed essentially no change, or else an increase, in mean coronary flow. These results

TABLE III

Tissue Data on Normal and Experimental Animals

\begin{tabular}{|c|c|c|c|c|c|c|c|c|c|c|c|c|}
\hline \multirow[b]{2}{*}{ Animal group } & \multicolumn{3}{|c|}{ Lactate } & \multicolumn{3}{|c|}{ Pyruvate } & \multicolumn{3}{|c|}{ Lactate/pyruvate } & \multicolumn{3}{|c|}{ Tissue water } \\
\hline & Outer & Inner & $P \ddagger$ & Outer & Inner & $P$ & Outer & Inner & $P$ & Outer & Inner & $P$ \\
\hline & \multicolumn{2}{|c|}{$m M^{*}$} & \multicolumn{4}{|c|}{$m M$} & & & & \multicolumn{2}{|c|}{$\%$} & \\
\hline $\begin{array}{l}\text { Normal }(n=8) \\
\quad \mathrm{SE} \pm\end{array}$ & $\begin{array}{l}0.547 \\
0.039\end{array}$ & $\begin{array}{l}0.604 \\
0.089\end{array}$ & NS & $\begin{array}{l}0.076 \\
0.007\end{array}$ & $\begin{array}{l}0.076 \\
0.004\end{array}$ & NS & $\begin{array}{l}7.8 \\
0.9\end{array}$ & $\begin{array}{l}8.6 \\
1.8\end{array}$ & NS & $\begin{array}{r}78 \\
1\end{array}$ & $\begin{array}{r}78 \\
0\end{array}$ & NS \\
\hline $\begin{array}{l}\text { Experimental I }(n=10) \\
\text { SE } \\
P \&\end{array}$ & $\begin{array}{c}0.817 \\
0.113 \\
\text { NS }\end{array}$ & $\begin{array}{c}0.873 \\
0.134 \\
\text { NS }\end{array}$ & NS & $\begin{array}{l}0.082 \\
0.006 \\
\text { NS }\end{array}$ & $\begin{array}{c}0.081 \\
0.007 \\
\text { NS }\end{array}$ & NS & $\begin{array}{r}10.8 \\
2.1 \\
\text { NS }\end{array}$ & $\begin{array}{r}11.6 \\
1.9 \\
\text { NS }\end{array}$ & NS & $\begin{array}{c}79 \\
1 \\
\text { NS }\end{array}$ & $\begin{array}{c}79 \\
1 \\
\text { NS }\end{array}$ & NS \\
\hline $\begin{array}{l}\text { Experimental II }(n=7) \\
\text { SE士 } \\
P \S\end{array}$ & $\begin{array}{l}1.065 \\
0.421 \\
\text { NS }\end{array}$ & $\begin{aligned} & 2.986 \\
& 1.023 \\
&<0.01\end{aligned}$ & $<0.05$ & $\begin{array}{l}0.071 \\
0.003 \\
\text { NS }\end{array}$ & $\begin{array}{c}0.072 \\
0.006 \\
\text { NS }\end{array}$ & NS & $\begin{array}{r}14.2 \\
4.7 \\
\text { NS }\end{array}$ & $\begin{array}{l}38.7 \\
10.8 \\
<0.01\end{array}$ & $<0.05$ & $\begin{array}{l}80 \\
0 \\
<0.05\end{array}$ & $\begin{array}{c}80 \\
0 \\
<0.01\end{array}$ & NS \\
\hline
\end{tabular}

* Calculated per kilogram of tissue.

$\ddagger$ Outer compared to inner.

$\$$ Compared to normal.

1604 D. M. Griggs, Jr., and C. C. Chen 
are similar to those obtained in other animal studies (1214), and clearly demonstrate an adjustment in tone of the coronary resistance vessels by the process of autoregulation to compensate for the reduction in perfusion pressure. Although the lowest aortic diastolic pressure at which mean coronary flow could be autoregulated was not established in this study, essentially constant flow was maintained in one experiment as pressure was lowered to $30 \mathrm{~mm} \mathrm{Hg}$. Others $(15,16)$ have reported a reduction in coronary flow at extremely low aortic diastolic pressures during acutely induced aortic insufficiency.

The alterations in the coronary flow pattern demonstrated in the present study are qualitatively and quantitatively similar to those reported by Karp and Roe (16). In that study aortic diastolic pressure averaged $47 \mathrm{~mm} \mathrm{Hg}$ and diastolic coronary flow $55 \%$ in five unanesthetized animals with chronic aortic insufficiency, and $33 \mathrm{~mm} \mathrm{Hg}$ and $25 \%$, respectively, in three anesthetized animals with acute aortic insufficiency. The data presented in Fig. 3 are in close agreement with those findings.

In recent years attention has been drawn to the observation made in the dog that myocardial tissue flow is unevenly distributed in the left ventricle under certain conditions. A relative subendocardial underperfusion has been shown to exist when coronary perfusion pressure is independently lowered beyond a certain limit $(2,5,17)$. Some investigators have contended that tissue flow is normally less in the subendocardium $(18,19)$ and that a state of relative hypoxia exists in the subendocardium of the well perfused heart (18-20). The underlying basis for subendocardial underperfusion is considered by most investigators to be related to a systolic intramyocardial tissue pressure gradient which increases from epicardium to endocardium (8). A current hypothesis is that flow is normally less in the subendocardium during systole due to this pressure gradient, but greater in the subendocardium during diastole due to autoregulation of flow by coronary resistance vessels (21). The net effect may be either an even or an uneven transmural distribution of flow, depending upon the interplay of a number of variables, including: coronary perfusion pressure, left ventricular pressure, the relative durations of systole and diastole, and the underlying tone of the coronary resistance vessels. Relationships have been established experimentally between the transmural distribution of myocardial flow and certain indexes of pressure in the coronary circulation and the ventricle which tend to bear out the validity of this hypothesis. The transmural distribution of flow has been shown to correlate with the coronary-ventricular pressure index (5), and the DPTI/TTI (2), as coronary vasomotor tone diminishes in response to various experimental maneuvers.
The previous studies raised an important question concerning the adequacy of subendocardial flow in aortic insufficiency, and one of the main purposes of the present investigation was to obtain information bearing on this question. It was felt that information on regional tissue flow would not permit a reliable assessment of the nutritional adequacy of such flow because oxygen consumption of the ventricle is reported to be increased in aortic insufficiency (14). Accordingly, metabolic data were sought that would reflect the balance between oxygen supply and demand in the inner and outer regions of the left ventricle in animals with aortic insufficiency. The results indicated that a myocardial oxygen imbalance limited to the inner region did develop in animals whose aortic diastolic pressure was in the lower range of pressures produced by aortic insufficiency. A tendency towards a higher inner region lactate concentration was noted below an aortic diastolic pressure of approximately $60 \mathrm{~mm} \mathrm{Hg}$. From the relationship shown in Fig. 3 between aortic diastolic pressure and the percentage of coronary flow occurring in diastole this pressure corresponds to a diastolic flow value of approximately $65 \%$. It is noteworthy that this is the same percent value reported by Buckberg et al. (2) to be critical for the redistribution of myocardial blood flow away from the subendocardium.

Both the aortic-ventricular pressure index developed by us and the DPTI/TTI developed by Buckberg et al. (2) were found to be more discriminating than aortic diastolic pressure alone for separating those animals with subendocardial metabolic changes from those without such changes. The critical value of 1.37 for the aortic-ventricular pressure index agreed well with the previously established value of 1.30 for uneven deposition of $\left[\mathrm{I}^{121}\right]$ iodoantipyrine in the ventricular wall due to coronary constriction (5). The critical DPTI/TTI value of 0.45 was lower than the previously reported value of 0.80 for relative subendocardial ischemia (2), but in close agreement with the more recently published value of 0.44 for ST-segment abnormalities in humans due to sudden strenuous exercise (22). The validity of both indexes in predicting inadequate oxygen delivery to the subendocardium appears to be confirmed by the present findings, with the aortic-ventricular pressure index giving a slightly better result in our hands.

From a statistical analysis of the data it was shown that the inner region lactate and lactate-to-pyruvate ratio values in Experimental Group II were not only higher than the outer region values, but also higher than normal. Associated with this was an elevated coronary sinus blood lactate level and a reduced myocardial lactate extraction, signifying that lactate was being released from the inner region in an amount sufficient to alter the net lactate balance of the ventricle. Despite this abnormality in myocardial lactate metabolism, the coronary sinus 
blood oxygen tension was not significantly different from normal. This has been noted previously in the presence of subendocardial anaerobic metabolism due to experimental aortic stenosis (10), and suggests that lactate production from less than the total myocardium can raise the coronary sinus level while total myocardial oxygen extraction is unchanged or even reduced.

The lack of inner region metabolic changes in Experimental Group I indicates that resistance vessels in this region were capable of responding in a physiologically satisfactory manner in some animals with aortic insufficiency. This would appear to represent strong evidence against the thesis that in the normal animal the subendocardium is relatively hypoxic due to insufficient coronary vasomotor tone (18-20).

The increase in myocardial tissue water percentage in Experimental Group II was unanticipated in view of our previous negative findings under somewhat similar metabolic conditions $(3,4,10)$. However, this difference from our previous results could be due to the fact that the experimental forcing was longer in the present study. The physical basis for the increase in tissue water was not explored, but with an increase in tissue lactate it possibly could be related to a change in cellular osmolarity (23).

Left ventricular end diastolic pressure was normal in this study, indicating that its elevation is not necessary for subendocardial ischemia. However, the results do not negate the possibility that an elevated left ventricular end diastolic pressure, by causing either a diastolic tissue pressure gradient or an increased myocardial wall stress, might play a role in the genesis of a subendocardial oxygen imbalance in patients with severe aortic insufficiency (24). Moreover, it should be emphasized that this study, carried out acutely in the anesthetized, open chest dog does not rule out the possibility of other deleterious or beneficial mechanisms in the clinical setting of acute or chronic aortic valvular insufficiency.

\section{ACKNOWLEDGMENTS}

This work was supported by National Institutes of Health grant HL-11876.

\section{REFERENCES}

1. Segal, J., W. P. Harvey, and C. Hufnagel. 1956. A clinical study of one hundred cases of severe aortic insufficiency. Am. J. Med. 21: 200.

2. Buckberg, G. D., D. E. Fixler, J. P. Archie, and J. I. E. Hoffman. 1972. Experimental subendocardial ischemia in dogs with normal coronary arteries. Circ. Res. $30: 67$.

3. Griggs, D. M., Jr., V. V. Tchokoev, and J. W. DeClue. 1971. Effect of beta-adrenergic receptor stimulation on regional myocardial metabolism: Importance of coronary vessel patency. Am. Heart J. 82: 492.

4. Griggs, D. M., Jr., V. V. Tchokoev, and C. C. Chen. 1972. Transmural differences in ventricular tissue substrate levels due to coronary constriction. Am. J. Phy'siol. 222 : 705.

$$
\text { D. M. Griggs, Jr., and C. C. Chen }
$$

5. Griggs, D. M., Jr., and Y. Nakamura. 1968. Effect of coronary constriction on myocardial distribution of iodoantipyrine- ${ }^{131} \mathrm{I}$. Am. J. Physiol. 215: 1082.

6. Hohorst, H. J. 1965. L- $(+)$-Lactate. Determination with lactic dehydrogenase and DPN. In Methods of Enzymatic Analysis. H. U. Bergmeyer, editor. Academic Press, Inc., New York. 266.

7. Segal, S., A. E. Blair, and J. B. Wyngaarden. 1956. An enzymatic spectrophotometric method for the determination of pyruvic acid in blood. J. Lab. Clin. Med. 48: 137.

8. Kirk, E. S., and C. R. Honig. 1964. An experimental and theoretical analysis of myocardial tissue pressure. Am. J. Physiol. 207 : 361.

9. Siegel, S. 1956. Nonparametric Statistics for the Behavioral Sciences. McGraw, New York. 75, 116, 184.

10. Griggs, D. M., Jr., C. C. Chen, and V. V. Tchokoev. 1973. Subendocardial anaerobic metabolism in experimental aortic stenosis. Am. J. Physiol. 224: 607.

11. Rowe, G. G., S. Afonso, J. E. Lugo, C. A. Castillo, W. C. Boake, and C. W. Crumpton. 1965. Coronary blood flow and myocardial oxidative metabolism at rest and during exercise in subjects with severe aortic valve disease. Circulation. 32: 251.

12. Wégria, R., G. Muelheims, J. R. Golub, R. Jreissaty, and J. Nakano. 1958. Effect of aortic insufficiency on arterial blood pressure, coronary blood flow and cardiac oxygen consumption. J. Clin. Invest. 37: 471.

13. West, J. W., H. Wendel, and E. L. Foltz. 1959. Effects of aortic insufficiency on circulatory dynamics of the dog. Circ. Res. $7: 685$.

14. Urschel, C. W., J. W. Covell, T. P. Graham, R. L. Clancy, J. Ross, Jr., E. H. Sonnenblick, and E. Braunwald. 1968. Effects of acute valvular regurgitation on the oxygen consumption of the canine heart. Circ. Res. 23: 33.

15. Green, H. D. 1936. The coronary blood flow in aortic stenosis, in aortic insufficiency and in arterio-venous fistula. Am. J. Physiol. 115: 94.

16. Karp, R. B., and B. B. Roe. 1966. Effect of aortic insufficiency on phasic flow patterns in the coronary artery. Ann. Surg. 164: 959.

17. Moir, T. W., and D. W. DeBra. 1967. Effect of left ventricular hypertension, ischemia, and vasoactive drugs on the myocardial distribution of coronary flow. Circ. Res. $21: 65$.

18. Kirk, E. S., and C. R. Honig. 1964. Nonuniform distribution of blood flow and gradients of oxygen tension within the heart. Am. J. Physiol. 207: 661.

19. Winbury, M. M. 1971. Redistribution of left ventricular blood flow produced by nitroglycerin. Circ. Res. 29 Suppl. I) : 140.

20. Moss, A. J. 1968. Intramyocardial oxygen tension. Cardiovas. Res. 2 : 314.

21. Moir, T. W. 1972. Brief Reviews: Subendocardial distribution of coronary blood flow and the effect of antianginal drugs. Circ. Res. 30: 621 .

22. Barnard, J. R., R. MacAlpin, A. A. Kattus, and G. D. Buckberg. 1973. Ischemic response to sudden strenuous exercise in healthy men. Circulation. 48: 936.

23. Iseri, L. T., J. R. Evans, and M. Evans. 1963. Pathogenesis of congestive heart failure. Correlation between anaerobic metabolism and plasma volume changes following exercise. Ann. Int. Med. 59: 788.

24. Kjekshus, J. K. 1973. Mechanism for flow distribution in normal and ischemic myocardium during increased ventricular preload in the dog. Circ. Res. 33: 489. 